\title{
Vascular endothelial growth factor-activated basophils in asthmatics
}

\author{
Krzysztof Gomułka', Jerzy Liebhart ${ }^{1}$, Andrzej Lange ${ }^{2,3}$, Wojciech Mędrala ${ }^{1}$
}

${ }^{1}$ Department of Internal Medicine, Pneumology and Allergology, Wroclaw Medical University, Wroclaw, Poland ²aboratory of Clinical Immunology, Hirszfeld Institute of Immunology and Experimental Therapy, Polish Academy of Sciences, Wroclaw, Poland

${ }^{3}$ Lower Silesian Cell Transplant Centre with the National Bank of Bone Marrow Donors, Wroclaw, Poland

\author{
Adv Dermatol Allergol 2020; XXXVII (4): 584-589
}

DOI: https://doi.org/10.5114/ada.2020.95954

\begin{abstract}
Introduction: Vascular endothelial growth factor (VEGF) is an angiogenic cytokine and a potential stimulator of permeability and lung neovascularization in asthmatics. It also plays an important role in the development of airway remodelling and in activation of many cells, including basophils.

Aim: To reveal the possible role of VEGF in the activation of basophils in asthmatics - subgroups with and without irreversible bronchoconstriction. Protein CD203C on the basophils surface was used as the activation marker. To define the possible pathway of basophils VEGF-activation, the influence of a genetic factor (polymorphism del18/ ins -2549-2567 in the VEGF-promoter region) was also considered.

Material and methods: Our study involved 82 patients with asthma (40 patients without and 42 patients with irreversible bronchoconstriction) and a group of 40 controls. The flow cytometric methods with anti-CD203c in the samples of basophils with increasing concentrations of VEGF was used for analysis of their activity. Genotyping for VEGF-promoter region was performed by PCR-based methods.

Results: Patients with asthma and del/del genotype showed more significant differences in the basophils activation after stimulation with increasing concentrations of VEGF than asthmatics with ins/ins and ins/del genotype $(p=0.023)$ and controls with del/del genotype $(p=0.0006)$.

Conclusions: Raised basophils VEGF-activation is characteristic for examined patients with asthma and might be associated with presence of polymorphism del18/ins -2549-2567 in the VEGF-promoter region. Furthermore, it may contribute to the development of airways remodelling - this pathway has not been considered yet.
\end{abstract}

Key words: asthma, basophils, CD-203c, del18, vascular endothelial growth factor.

\section{Introduction}

The family of vascular endothelial growth factors (VEGF) consists of five structurally similar forms: VEGF-A (the prototype, discovered first and called generally VEGF), VEGF-B, VEGF-C, VEGF-D and placenta growth factor (PGF). VEGF is a homodimeric glycoprotein, weight $46 \mathrm{kDa}$, its gene is located on 6p21.3. VEGF variants with a different number of amino-acids are produced in human cells by alternative splicing (for VEGF-A, VEGF-B and PGF) and processing (VEGF-A, VEGF-C and VEGF-D). Among them, $V E G F_{121}$ and $V E G F_{165}$ are generated by macrophages, platelets, neutrophils and epithelial cells as soluble and freely diffusible forms, whereas VEGF ${ }_{189}$ and $V E_{206}$ are associated with cells' surface. VEGF acts biologically by recep- tors tyrosine kinases (RTKs - VEGFR-1, VEGFR-2, VEGFR-3), which differ considerably in signalling properties and are expressed by activated macrophages, endothelial cells or epithelial cells [1-3]. VEGF is the main regulator of vascular development and vessels function in health and disease. VEGF seems to be a key regulator of physiological angiogenesis during post-natal and skeletal growth, reproductive functions, embryogenesis with endothelial cells' growth, menstrual cycle and wound healing $[4,5]$. VEGF has also been implicated in pathological angiogenesis in several malignancies, e.g. in tumour growth and the formation of metastasis, age-related macular degeneration, autoimmune diseases, allergic and metabolic disorders, cardio-vascular and dermatological diseases [6, 7]. VEGF

Address for correspondence: Krzysztof Gomułka MD, PhD, Department of Internal Medicine, Pneumology and Allergology, Wroclaw Medical University, 66 M. Curie-Skłodowskiej St, 50-369 Wroclaw, Poland, phone: +48 71784 26 47, fax: +48 7132709 54, e-mail: krzysztof.gomulka@umed.wroc.pl

Received: 27.09.2018, accepted: 7.02.2019. 
has been considered as one of the molecules important in asthma, lung remodelling and activation of cells involved in the inflammatory process, which include basophils. Basophils synthesize IL-4 and IL-13, what suggests that they participate in IgE synthesis and Th2 polarization. These cells are also able to produce pro-angiogenic molecules, like IL-3 and VEGF. Despite their small numbers in peripheral blood, basophils are involved in disorders with immune background, such as allergies, autoimmune and infectious diseases, cancers and immunodeficiency [8-10]. Detection of activated basophils by indication of CD203c marker on the membrane using the flow cytometry has been shown to be a useful tool. Up-regulation of CD203c on basophils' surface is the result of FceRI-mediated reaction and plays a role in cytokine-mediated activation of these cells [11, 12].

\section{Aim}

The aim of the present study was to reveal the possible relationship between CD203c expression as a marker of basophils activation by VEGF in asthmatics - in subgroups with and without irreversible bronchoconstriction. The influence of the genetic factor as the del18/ins -2549-2567 polymorphism in the promoter region of the VEGF's gene was also considered.

\section{Material and methods}

\section{Study group}

The study involved 122 individuals ( 80 women) aged from 20 to 70 years, of whom 40 participants from the control group (26 women) had normal pulmonary function and did not present any allergies. In a group of 82 patients ( 54 women) aged from 23 to 69 years, the diagnosis of asthma was established according to recommendations from the Global Initiative for Asthma (GINA 2011). The degree of asthma severity ranged from sporadic to severe persistent. Considering the bronchodilation test, patients with asthma were divided into two subgroups: patients without irreversible bronchoconstriction (40 patients; 29 women; aged from 23 to 69 years) and patients with irreversible bronchoconstriction (42 patients; 25 women; aged from 24 to 69 years). After genotyping of VEGF polymorphism, the results provide three genotype classifications: homozygous mutation (ins/ins), heterozygous mutation (ins/del) and no mutation or the so-called wild genotype (del/del). Therefore, participants from all the examined group were divided into two phenotypic categories: no mutation - del (del/del) and mutation - ins (ins/ins or ins/del). The protocol for our study was approved by the Ethics Committee of the Wroclaw Medical University, Poland (No. KB 68/2011). Characteristics of the study population are shown in Table 1.

\section{Bronchodilation test}

The pulmonary function test with the bronchodilation test, defining among others forced expiratory volume in $1 \mathrm{~s}\left(\mathrm{FEV}_{1}\right)$ and forced vital capacity (FVC) values, were established using MasterScope CT Spirometer (Erich Jaeger $\mathrm{GmbH}$, Wurzburg, Germany). Each parameter was estimated three times and showed as a percentage of predicted values; the best scores were used for

Table 1. The population data

\begin{tabular}{|c|c|c|c|}
\hline Parameter & $\begin{array}{l}\text { Asthmatics - reversible } \\
\text { bronchoconstriction }\end{array}$ & $\begin{array}{l}\text { Asthmatics - irreversible } \\
\text { bronchoconstriction }\end{array}$ & Controls \\
\hline$N$ & 40 & 42 & 40 \\
\hline $\begin{array}{l}\text { Female gender } \\
n(\%)\end{array}$ & $29(72.5)$ & $25(59.52)$ & $26(65)$ \\
\hline $\begin{array}{l}\text { Age [years] } \\
\text { mean } \pm S D\end{array}$ & $50.03 \pm 13.65$ & $53.71 \pm 10.40$ & $47.95 \pm 13.66$ \\
\hline $\begin{array}{l}\text { Mean disease duration } \\
\text { [years] }\end{array}$ & 10.04 & 21.94 & - \\
\hline $\begin{array}{l}\mathrm{FEV}_{1} \% \\
\text { mean } \pm \mathrm{SD}\end{array}$ & $90.12 \pm 17.25$ & $56.05 \pm 18.62$ & $104.81 \pm 15.37$ \\
\hline $\begin{array}{l}\mathrm{FVC} \% \\
\text { mean } \pm \mathrm{SD}\end{array}$ & $98.49 \pm 13.89$ & $72.21 \pm 19.31$ & $101.36 \pm 13.26$ \\
\hline $\begin{array}{l}\text { Phenotypic categories } \\
\text { del/ins, } n\end{array}$ & $27 / 13$ & $34 / 8$ & $22 / 18$ \\
\hline Smoking (yes), $n$ & 6 & 15 & 11 \\
\hline inhGCS, $n$ & 27 & 37 & - \\
\hline LABA, $n$ & 28 & 38 & - \\
\hline
\end{tabular}

del/ins - deletion/insertion of VEGF gene's polymorphism, FEV \% - forced expiratory volume in $1 \mathrm{~s}$, \% of predicted, FVC\% - forced vital capacity, \% of predicted, $S D$ - standard deviation, inh GCS - inhaled corticosteroids, $L A B A$ - long-acting $\beta 2$ agonists. 
A

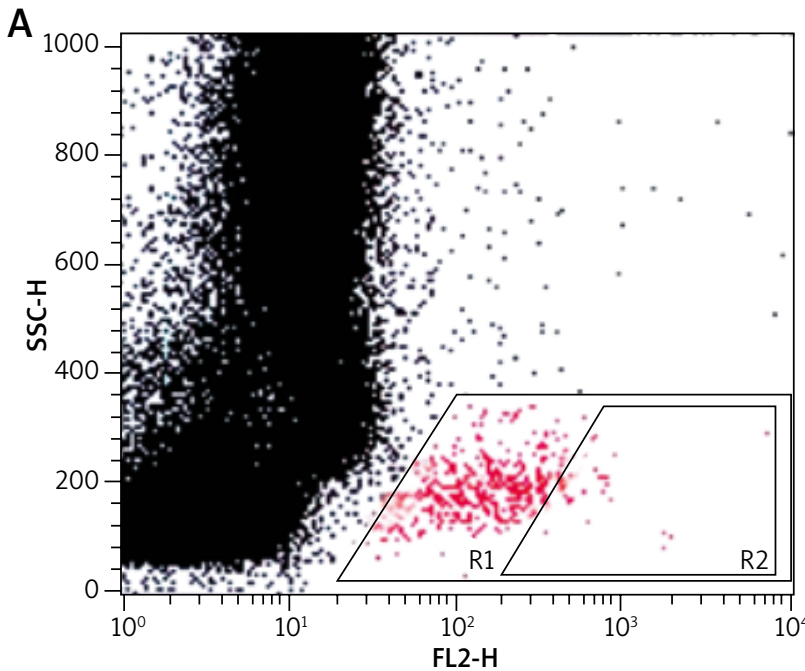

Figure 1. Population of basophils (gate R1) with the active cells (gate R2) in a non-stimulated negative control sample

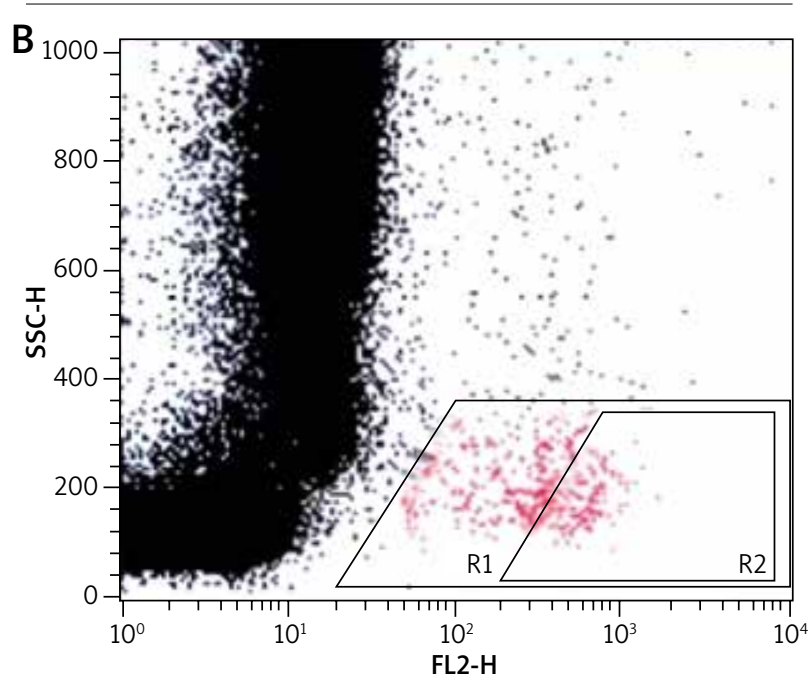

Figure 2. Population of basophils (gate R1) with the active cells (gate R2) in a positive control sample

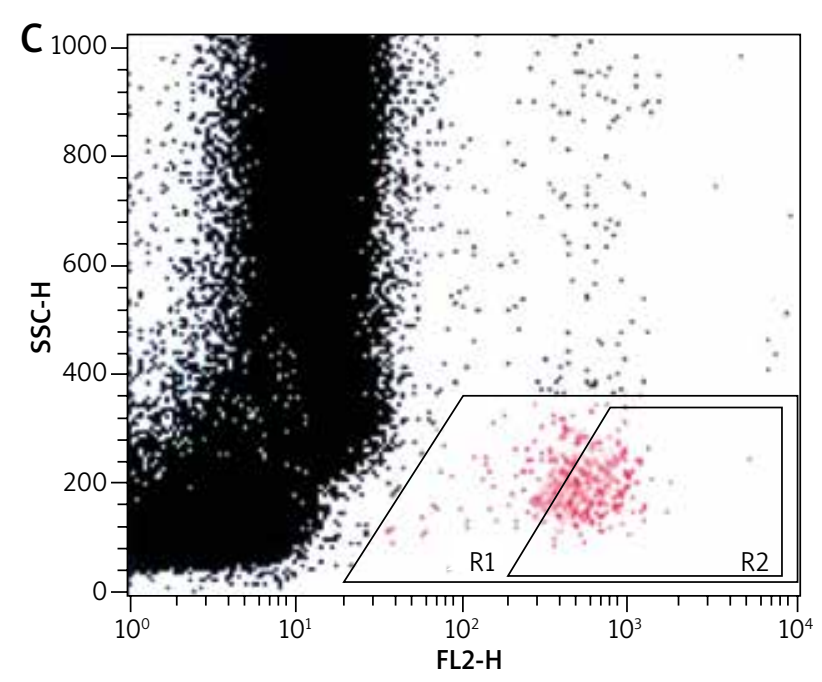

Figure 3. Population of basophils (gate R1) with the active cells (gate R2) in a sample containing VEGF further analysis. In asthmatics, the bronchodilation test was performed after inhalation with $5 \mathrm{mg}$ of salbutamol (SteriNeb Salamol; Teva Pharmaceuticals, Warsaw, Poland) administered with the jet nebulizer (Model 4650-U, Devilbiss, Heston, UK). The post-bronchodilator values of $\mathrm{FEV}_{1} / \mathrm{FVC}<0.7$ and $\mathrm{FEV}_{1}<0.8$ predicted were taken as a criterion of irreversible bronchoconstriction.

\section{Basophils activation}

For the flow cytometric method, following samples were used: sample without VEGF as a non-stimulated negative control (patient background - Pb), sample with fMLP (NFormylmethionyl-leucyl-phenylalanine) in concentration of $10^{-6} \mathrm{M}$ as a positive control (PC) and two samples containing VEGF in concentration of $250 \mathrm{ng} / \mathrm{ml}$ and $500 \mathrm{ng} / \mathrm{ml}$. All samples contained $100 \mu \mathrm{l}$ blood taken to the $4.5 \mathrm{ml}$ tubes with lithium heparin (Saerstedt AG \& Co., Nümbrecht, Germany) and $100 \mu \mathrm{l}$ RPMI-1640 Medium (Institute of Immunology and Experimental Therapy, Wroclaw, Poland), fMLP (Institute of Immunology and Experimental Therapy, Wroclaw, Poland) or VEGF (BD Biosciences Pharmingen, San Diego, USA). Samples were incubated in the atmosphere supplemented with $5 \% \mathrm{CO}_{2}$ at $37^{\circ} \mathrm{C}$ for 60 min (Incubator ASSAB, Stockholm, Sweden). After incubation, $20 \mu$ l of edentate disodium EDTA (BD Biosciences Pharmingen, San Diego, USA) was added and samples were centrifuged at 1600 $\mathrm{rev} / \mathrm{min}$ for $10 \mathrm{~min}$. Then, the supernatant was removed, $100 \mu$ l of PBS (Institute of Immunology and Experimental Therapy, Wroclaw, Poland) with $1 \%$ bovine serum albumin (Sigma-Aldrich, St. Louis, USA) and $10 \mu$ lo anti-CD203c (Immunotech S.A.S., Marseille, France) were added and incubated in the darkness in $25^{\circ} \mathrm{C}$ for $30 \mathrm{~min}$. After incubation, $2 \mu \mathrm{l}$ fluid for the cells' lysis (BD Biosciences Pharmingen, San Diego, USA) was added and after $10 \mathrm{~min}$ at room temperature, the samples were centrifuged at $1600 \mathrm{rev} / \mathrm{min}$ for $5 \mathrm{~min}$. Afterwards, the supernatant was removed and for each sample $3 \mathrm{ml}$ of PBS was added and centrifuged $5 \mathrm{~min}$ at room temperature at $1600 \mathrm{rev} / \mathrm{min}$. To preserve the cells, $200 \mu$ l of PBS with 1.5\% paraformaldehyde (Sigma-Aldrich, St. Louis, USA) was added. From each examined sample, $10^{5}$ cells were collected using a FACScan flow cytometer (Becton Dickinson, San Diego, USA) and expression of antigen CD203c on basophils surface was used for analysis of their activity. In total population of basophils (gate R1), the percentage of active cells was identified (gate R2) - it is shown in Figures 1-3. The above method used for basophils activation test was coincident with that described by Kahlert et al. [13] with own modification (two samples containing VEGF in selected experimentally concentration of $250 \mathrm{ng} / \mathrm{ml}$ and $500 \mathrm{ng} / \mathrm{ml}$ ).

\section{Genotyping of VEGF's polymorphism}

DNA was isolated from blood lymphocytes using a DNA isolation kit (QiAmp DNA Blood Mini kit, Syngen Biotech, Wroclaw, Poland). All patients from asthmatics and controls groups were genotyped by polymerase 
chain reaction (PCR) according to the method by Lachheb et al. [14] with the own modification. The pair of primers (F: 5'-cctggagcgttttggttaaa-3' and R: 5'-atataggaagcagctggaa-3') was used for the verification of the addition or the loss of 18 base pairs (18 bp) within the promoter region in VEGF gene at a position -2549-2567. The concentration of the isolated DNA and its purity was identified by spectrophotometer (NanoDrop ThermoScientific, Thermo Fisher Scientific, Wilmington, USA). The total volume of the PCR was $25 \mu \mathrm{l}$ containing $100 \mathrm{ng}$ of genomic DNA, $0.5 \mathrm{mmol} / \mathrm{l}$ of nucleotide, $3 \mathrm{pmol}$ of suitable starter, $1 \times$ Taq Buffer and 0.5 units of Taq-DNA polymerase (Taq DNA Polimeraza E2500-02 - 5000u, EURx, Gdansk, Poland); the final $\mathrm{MgCl}_{2}$ level was $4 \mathrm{mmol} / \mathrm{l}$. The PCR comprised an initial denaturation step $\left(95^{\circ} \mathrm{C}\right.$ for $\left.15 \mathrm{~min}\right)$, then 35 cycles $\left(95^{\circ} \mathrm{C}\right.$ for $\left.30 \mathrm{~s}\right)$, primer annealing $\left(54^{\circ} \mathrm{C}\right.$ for $30 \mathrm{~s}$ and $72^{\circ} \mathrm{C}$ for $\left.30 \mathrm{~s}\right)$ and a final extension step $\left(72^{\circ} \mathrm{C}\right.$ for $10 \mathrm{~min}$ ). The PCR products were analysed using agarose gel electrophoresis followed by ethidium bromide staining and ultraviolet visualization.

\section{Statistical analysis}

Statistical analysis was performed using of program Statistica 10 for Windows. Laboratory data were all reported as medians. Comparisons between groups were performed using ANOVA test of Kruskal-Wallis. A p-value $<0.05$ was considered statistically significant.

\section{Results}

In the non-stimulated negative sample $(\mathrm{Pb})$, the percentage of activated basophils was at a similar level in all tested persons. In controls, the median of activated cells was $2.89 \%$ (min. 1.06\%; max. 3.2\%) - in controls with del phenotype it was $2.9 \%$ ( $\min .1 .06 \%$; max. 3.2\%) and in controls with ins phenotype it was $2.87 \%$ (min. $1.71 \%$; max. $2.9 \%$ ) and this difference was statistically significant $(p=0.03)$. In asthmatics, the median of activated basophils was $2.81 \%$ ( $\min .1 .31 \%$; max. 8.63\%) - in a subgroup with reversible bronchoconstriction it was $2.87 \%$ (min. 1.31\%; max. $8.63 \%$ ) and in a subgroup with irreversible bronchoconstriction it was $2.7 \%$ (min. 1.83\%; max. 4.42\%). Asthmatics with del phenotype and ins phenotype had a similar level of activated basophils $(\mathrm{Me}=2.7 \%(\min .1 .31 \%$; $\max .8 .63 \%)$ vs $M e=2.92 \%$ (min. 1.83\%; max. 3.21\%)) and this difference was not statistically significant $(p=0.18)$.

After stimulation of fMLP (positive control), the percentage of activated CD203c+ basophils was higher than in a non-stimulated negative sample. In controls, the median of these cells was $6.43 \%$ (min. 0.0; max. $42.02 \%$ ) - in controls with del phenotype it was $5.38 \%$ (min. $0.93 \%$; max. 38.49\%) and in controls with ins phenotype it was $27.9 \%$ (min. 0.0; $\max .42 .02 \%$ ) and this difference was statistically significant $(p=0.03)$. In asth- matics, the median of activated CD203c+ basophils was $7.46 \%$ (min. 0.26\%; max. 67.33\%) - in a subgroup with reversible bronchoconstriction it was 5.55\% (min. 0.45\%; max. $47.54 \%$ ) and in a subgroup with irreversible bronchoconstriction it was 9.91\% (min. 0.26\%; max. 67.33\%). Asthmatics with del phenotype and ins phenotype had a different level of basophils ( $\mathrm{Me}=8.86 \%$ ( $\min .0 .56 \%$; $\max .67 .33 \%)$ vs $M e=4.38 \%(\min .0 .26 \%$; $\max .34 .2 \%)$ and it was statistically significant $(p=0.02)$.

After addition of VEGF in concentration $250 \mathrm{ng} / \mathrm{ml}$, the median of activated basophils in asthmatics rose to a mean value of $1.98 \%$ (min. 0.0; $\max .8 .31 \%$ ) and was higher than in controls (1.08\% (min. 0.0; max. 19.8\%)). In a subgroup with reversible bronchoconstriction the median of activated basophils was 1.89\% (min. 0.0; max. $6.34 \%$ ) and in a subgroup with irreversible bronchoconstriction it was $2.67 \%$ (min. 0.0; max. 8.31\%). After considering presence of del/del genotype, there was a significant difference $(p=0.0007)$ between percentage of activated $\mathrm{CD} 203 \mathrm{c}+$ basophils in asthmatics and controls $(\mathrm{Me}=2.05 \%(\min .0 .0 ; \max .8 .31 \%)$ vs $M e=0.86 \%(\mathrm{~min}$. 0.0 ; $\max .19 .8 \%)$ ).

After increase in the VEGF concentration to $500 \mathrm{ng} /$ $\mathrm{ml}$, the median of activated basophils in controls rose to a mean value of $1.29 \%$ (min. 0.0; max. 67.96\%) and was higher in persons with del phenotype (1.11\% (min. 0.0; max. 67.96\%)) than with ins phenotype (1.63\% (min. 0.0; max. $5.13 \%)$ ). In asthmatics, this median was $2.01 \%$ (min. 0.0; max. 38.36\%) - with reversible bronchoconstriction it was $1.97 \%$ (min. $0.25 \%$; max. $38.36 \%$ ) and with irreversible bronchoconstriction it was $2.41 \%$ (min. 0.0; $\max .6 .3 \%$ ). After considering the genetic factor, there was a significant difference $(p=0.02)$ between percentage of activated CD203c+ basophils in asthmatics del/del genotype vs ins/ins and ins/del genotype ( $\mathrm{Me}=2.36 \%$ (min. 0.04\%; $\max .38 .36 \%$ ) vs $M e=1.58 \%$ (min. 0.0; $\max$. $6.49 \%)$ ). The data are shown in Figures 4 A-D.

\section{Discussion}

Vascular endothelial growth factor, described by Senger et al. [15] and then by Ferrara and Henzel [16], is an important angiogenic factor. It is an essential molecule for the growth of new blood and lymph vessels in adult life, in health and during disorders, likewise allergic. Authors have observed a relationship between circulating VEGF and intensity of neovascularization and inflammation in airways in asthmatics [17-19]. Increased concentration of VEGF was present in asthmatics in comparison with healthy controls in the sample of induced-sputum, in the bronchoalveolar lavage or in bronchial biopsies [20, 21]. VEGF increases the number of vessels in the lamina propria of airways in asthmatics. It also affects the airways hyperactivity and thickening of the bronchial wall during lung remodelling [22, 23]. 
A
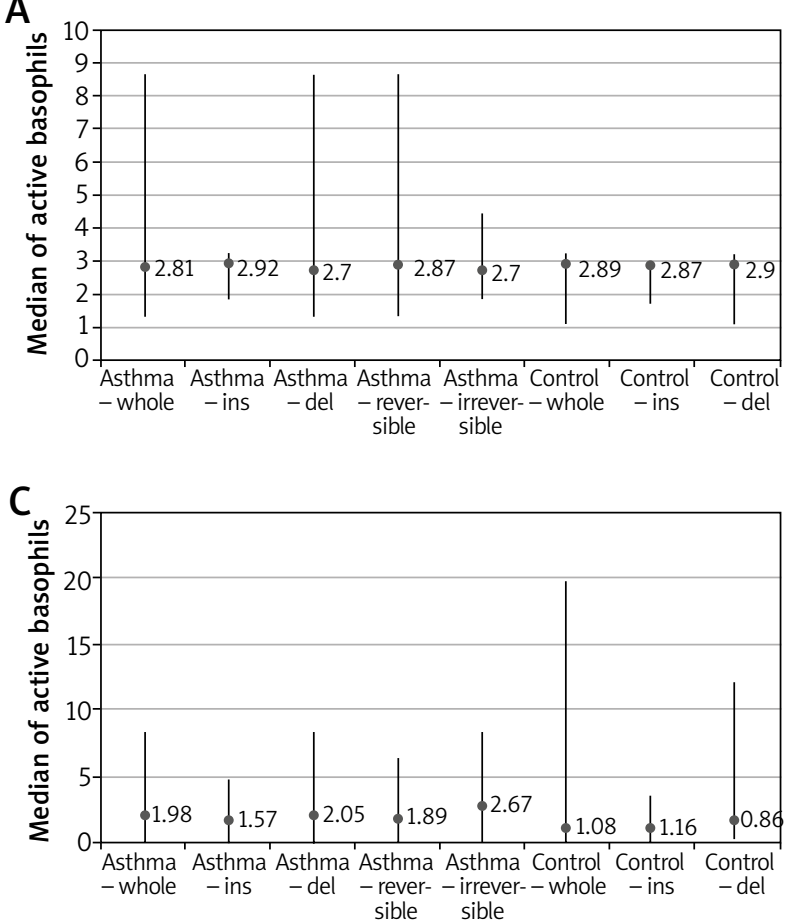

B
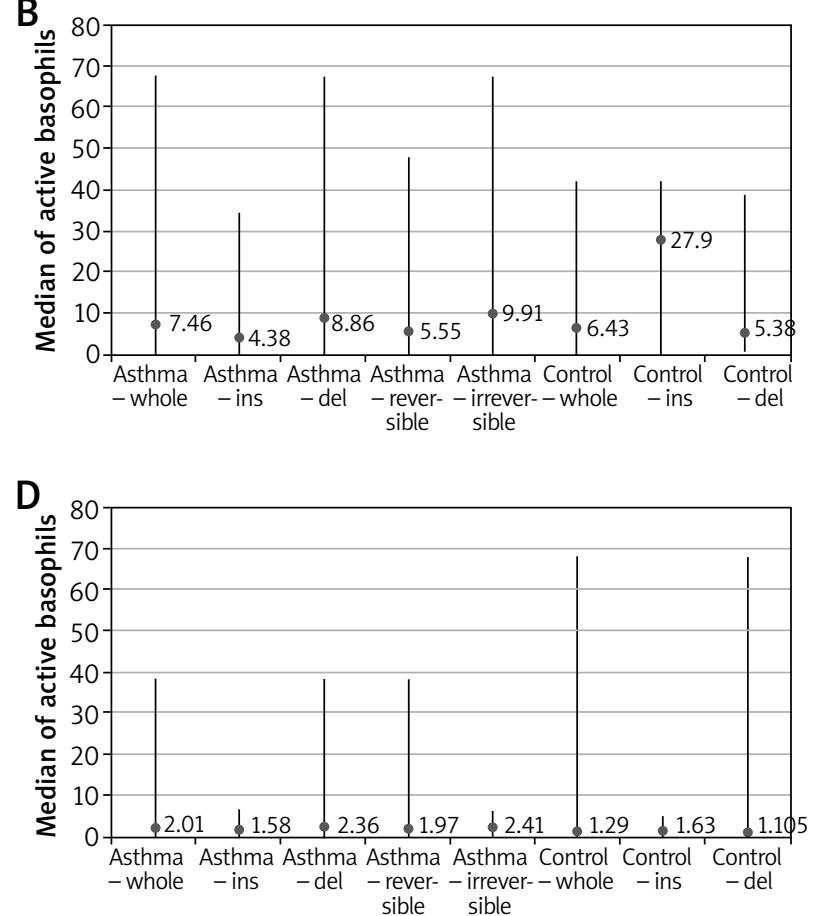

Figure 4. CD203c expression as a degree of basophil activation in non-stimulated sample (A), in simulated positive control (B) and in tested groups after stimulation with $250 \mathrm{ng} / \mathrm{ml}$ (C) and $500 \mathrm{ng} / \mathrm{ml}$ (D) VEGF

The angiogenic process requires an interaction among specific growth factors (e.g. VEGF) and cell types (e.g. basophils, mast cells). Available studies indicate that basophils can synthesize and release VEGF and are susceptible to VEGF-activation. De Paulis et al. [24] observed a high expression of mRNA for VEGF and VEGF-R in circulating basophils and intracellular presence of VEGF in basophils located in airways. Afterwards, the VEGF release after basophils activation and increasing chemotaxis was shown. Immunologically activated human basophils selectively express not only isoforms of VEGF-A and VEGF-B but also release angiopoietin-1 that activates mast cells and in this way might participate in the complex network involving inflammatory angiogenesis [25]. Observations by Lichtenstein et al. [26] confirmed the role of basophils in asthma - there was a positive correlation between the number of basophils obtained from bronchoalveolar lavage and the bronchial hyperreactivity. Furthermore, migration of activated basophils to the airways was observed during asthma exacerbation which was associated with an increased number of cells in sputum. The basophils activation test (BAT) with the flow cytometry method is a reliable tool for monitoring basophils activation by detecting expression of markers on the membrane, e.g. CD63 or CD203c [27-29]. Moreover, the possible relationship of the VEGF gene polymorphism with the VEGF-activated basophils in asthmatics has not been specified yet. Therefore, the purpose of the present study was to analyse the activity of basophils in all groups of patients, using the flow cytometric methods with anti-CD203c and with samples containing fMLP (positive control), the increasing concentrations of VEGF $(250 \mathrm{ng} / \mathrm{ml}$ and $500 \mathrm{ng} / \mathrm{ml})$ and in the sample of unstimulated cells (negative control). The influence of a genetic factor (polymorphism del18/ins -2549 -2567 in the VEGF-promoter region) was also considered.

Having basophils activity expressed as cells with the receptor CD203c on the surface, the median percentage of the activated basophils in the unstimulated cells sample was found to be similar in the control group and in the groups with asthma, regardless of the genotype del18/ins or the severity of the bronchoconstriction. After stimulation of basophils with $\mathrm{FMLP}$, the statistically significant difference in the activity of these cells was revealed between the control group and in patients with asthma, also having considered presence of del18/ins genotype. Analysis of the activated basophils after stimulation with increasing concentrations of VEGF showed a similar percentage of activated cells in each group of patients. The statistically significant difference was seen in patients with asthma and different genotypes del18 vs ins of the VEGF gene as well as between the group of patients with asthma with del18 genotype and the control group with del18 genotype.

Obtained data indicate that the stimulation of basophils with VEGF enhances the activity of these cells. Additionally, in patients with del18 genotype both in the control and asthmatic group, the activity of basophils after VEGF stimulation remains higher, compared with the sample of unstimulated cells.

Our study has potentially significant drawbacks - the use of only one marker (CD203c) to determine the degree of basophil activation, experimental selection of only two VEGF concentrations and lack of occurrence of inhalation allergy that may affect the BAT results. With the promis- 
ing obtained results, it is possible to extend our work in the future by other markers of basophil activation (e.g. CD164, CD63) and other simulating concentrations of VEGF or/and other cytokines.

\section{Conclusions}

We present our findings to draw attention to the potential role of the VEGF and its genetic variants in the basophil activation. Undoubtedly, the pathomechanism of the airways remodelling in asthma is complex. Our results seem to form a logical sequence and may indicate another pathway of the process which has not been subjected to consideration yet. Polymorphism del18 in the promoter region - 2549 -2567 of the VEGF gene is related to the increased activation of basophils by VEGF and, because of that, with the greater predisposition to release mediators from these cells. Both processes contribute to the development of remodelling. The above hypothesis is worth a further investigation to be conducted on a larger sample of patients.

\section{Acknowledgments}

The authors thank Barbara Majewska for performing spirometry tests, Emilia Królewicz for laboratory analyses, Przemystaw Czajka for genotyping and Urszula Gładysz for statistical analysis of the data.

This study was supported by the Grant for the Young Scientists No. Pbmn 150 from Medical University in Wroclaw, Poland (granted to KG).

\section{Conflict of interest}

The authors declare no conflict of interest.

\section{References}

1. Gover-Proaktor A, Granot G, Shapira S, et al. Ponatinib reduces viability, migration, and functionality of human endothelial cells. Leuk Lymphoma 2017; 58: 1455-67.

2. Ferrara N, Gerber HP, LeCouter J. The biology of VEGF and its receptors. Nat Med 2003; 9: 669-76.

3. Gomutka K, Liebhart J. Vascular endothelial growth factor-structure, function and role in airways inflammation and the clinical course of asthma. Pneumonol Alergol Pol 2009; 77: 549-53.

4. Xin H, Zhong C, Nudleman E, et al. Evidence for pro-angiogenic functions of VEGF-Ax. Cell 2016; 167: 275-84.

5. Yamamoto H, Rundqvist $\mathrm{H}$, Branco C, et al. Autocrine VEGF isoforms differentially regulate endothelial cell behavior. Front Cell Dev Biol 2016; 4: 99.

6. Grąbczewska Z, Dębski R, Góralczyk K, et al. Associations between selected angiographic parameters and the number of $\mathrm{CD} 34^{+}$cells and plasma levels of vascular endothelial growth factor and angiogenin in patients with ST-segment elevation myocardial infarction. Pol Arch Med Wewn 2015; 125: 132-40.

7. Przepiera-Będzak H, Fischer K, Brzosko M. Serum levels of angiogenic cytokines in psoriatic arthritis and SAPHO syndrome. Pol Arch Med Wewn 2013; 123: 297-302.

8. Marone G, Borriello F, Varricchi G, et al. Basophils: historical reflections and perspectives. Chem Immunol Allergy 2014; 100: 172-92.
9. Schneider E, Thieblemont N, De Moraes ML, et al. Basophils: new players in the cytokine network. Eur Cytokine Netw 2010; 21: 142-53.

10. Marone G, Triggiani M, Genovese A, et al. Role of human mast cells and basophils in bronchial asthma. Adv Immunol 2005; 88: 97-160.

11. Wolanczyk-Medrala A, Gogolewski G, Liebhart J, et al. A new variant of the basophil activation test for allergen-induced basophil CD63 upregulation. The effect of cetirizine. J Investig Allergol Clin Immunol 2009; 19: 465-73.

12. Boumiza R, Debard AL, Monneret G. The basophil activation test by flow cytometry: recent developments in clinical studies, standardization and emerging perspectives. Clin Mol Allergy 2005; 3: 9.

13. Kahlert H, Cromwell O, Fiebig H. Measurement of basophilactivating capacity of grass pollen allergens, allergoids and hypoallergenic recombinant derivatives by flow cytometry using anti-CD203c. Clin Exp Allergy 2003; 33: 1266-72.

14. Lachheb J, Chelbi H, Dhifallah IB, et al. Association of vascular endothelial growth factor polymorphisms with asthma in Tunisian children. Gene Regulation and Systems Biology 2008; 2: 89-96.

15. Senger DR, Galli SJ, Dvorak AM, et al. Tumor cells secrete a vascular permeability factor that promotes accumulation of ascites fluid. Science 1983; 219: 983-5.

16. Ferrara N, Henzel WJ. Pituitary follicular cells secrete a novel heparin-binding growth factor specific for vascular endothelial cells. Biochem Biophys Res Commun 1989; 161: 851-8.

17. Czarniakowska-Bołtuć M, Ziętkowski Z, Bodzenta-Łukaszyk A. Role of selected growth factors in asthma. Alergia Astma Immunol 2012; 17: 172-9.

18. Meyer N, Akdis CA. Vascular endothelial growth factor as a key inducer of angiogenesis in the asthmatic airways. Curr Allergy Asthma Rep 2013; 13: 1-9.

19. Li X, Wilson JW. Increased vascularity in the bronchial mucosa in mild asthma. Am J Respir Crit Care Med 1997; 156: 229-33.

20. Lee C, Ma B, Takyar S, et al. Studies of vascular endothelial growth factor in asthma and chronic obstructive pulmonary disease. Proc Am Thorac Soc 2011; 8: 512-5.

21. Koczy-Baron E, Kasperska-Zając A. The role of vascular endothelial growth factor in inflammatory processes. Postepy Hig Med Dosw 2014; 68: 57-65.

22. Barbato A, Turato G, Baraldo S, et al. Airway inflammation in childhood asthma. Am J Respir Crit Care Med 2003; 168: 798803.

23. Abdel-Rahman AM, el-Sahrigy SA, Bakr SI. A comparative study of two angiogenic factors: vascular endothelial growth factor and angiogenin in induced sputum from asthmatic children in acute attack. Chest 2006; 129: 266-71.

24. de Paulis A, Prevete N, Fiorentino I, et al. Expression and functions of the vascular endothelial growth factors and their receptors in human basophils. J Immunol 2006; 177: 7322-31.

25. Marone G, Varricchi G, Loffredo S, et al. Mast cells and basophils in inflammatory and tumor angiogenesis and lymphangiogenesis. Eur J Pharmacol 2016; 5: 146-51.

26. Lichtenstein LM, Bochner BS. The role of basophils in asthma. Ann NY Acad Sci 1991; 629: 48-61.

27. Kim SY, Kim JH, Jang YS, et al. The basophil activation test is safe and useful for confirming drug-induced anaphylaxis. Allergy Asthma Immunol Res 2016; 8: 541-4.

28. Potapińska O, Demkow U, Wąsik M. Flow cytometric basophils activation test as a method of allergy diagnosis. Pneumonol Alergol Pol 2009; 77: 152-8.

29. de Weck AL, Sanz ML, Gamboa PM, et al. Diagnostic tests based on human basophils: more potentials and perspectives than pitfalls. Int Arch Allergy Immunol 2008; 146: 177-89. 